\title{
ESTIMASI EMISI KARBONDIOKSIDA DARI SEKTOR PERMUKIMAN DI KOTA YOGYAKARTA MENGGUNAKAN IPCC GUIDELINES
}

\author{
Qorry Nugrahayu ${ }^{1)}$; Nabila Khumaira Nurjannah ${ }^{2)}$; Luqman Hakim ${ }^{3)}$ \\ 1) Pusat Studi Perubahan Iklim dan Kebencanaan Universitas Islam Indonesia \\ 2,3) Program Studi Teknik Lingkungan, Fakultas Teknik Sipil dan Perencanaan, Universitas Islam Indonesia; \\ Email : qorrynugrahayu@ uii.ac.id ${ }^{1)}$
}

\begin{abstract}
Abstrak
Kota Yogyakarta mengalami peningkatan jumlah penduduk, melihat luas penggunaan lahan yang di dominasi oleh perumahan yaitu seluas 2.100,71 Ha dari total luas lahan Kota Yogyakarta 3.250 Ha (SLHD Kota Yogyakarta,2014). Semakin meningkat jumlah penduduk semakin besar lahan yang dipergunakan untuk perumahan/permukiman akan menyebabkan semakin besar penggunaan bahan bakar memasak yang digunakan. Penelitian ini menjadi penting untuk dibahas karena hal tersebut jika dikaitkan dengan adanya PP No. 61 Tahun 2011 tentang rencana Aksi Nasional Penurunan Emisi Gas Rumah Kaca (GRK) dan PP No. 71 Tahun 2011 tentang Penyelenggaraan Inventarisasi Emisi GRK Nasional yang menyatakan bahwa setiap daerah pemerintahan baik kabupaten/kota wajib melakukan kegiatan inventarisasi GRK. Penelitian ini bertujuan untuk mengestimasi emisi tapak karbon dan pemetaannya di Kota Yogyakarta. Berdasarkan hasil perhitungan emisi karbon di setiap kecamatan menunjukan emisi tertinggi berada pada kecamatan Gedontengen yaitu sebesar 994.033 ton $\mathrm{CO}_{2} /$ rumah tangga.tahun. sedangkan untuk emisi terendah ada pada kecamatan Pakualaman yaitu sebesar 20.811 ton $\mathrm{CO}_{2} /$ rumah tangga.tahun. Berdasarkan hasil pemetaan dapat diketahui bahwa dari 14 kecamatan ada 3 kecamatan berada pada emisi skala sangat tinggi 994.000 - 528.000 ton $\mathrm{CO}_{2} /$ rumah tangga.tahun, 3 kecamatan berada pada emisi skala tinggi 528.000 - 186.000 ton $\mathrm{CO}_{2} /$ rumah tangga.tahun, 1 kecamatan berada pada skala emisi sedang 95.000 ton $\mathrm{CO}_{2} /$ rumah tangga.tahun, 5 kecamatan berada pada skala rendah 95.000- 34.460 ton $\mathrm{CO}_{2} /$ rumah tangga.tahun, dan 2 kecamatan berada pada skala sangat rendah $34.460-20.811$ ton $\mathrm{CO}_{2} /$ rumah tangga.tahun.
\end{abstract}

Kata Kunci : Emisi CO2, IPCC, Kota Yogyakarta, Pemetaan, Permukiman

\begin{abstract}
The population of Yogyakarta City has been continously increasing. This can be seen from the extensive of land use which is dominated by the residential areas. The residential area in Yogyakarta covers 2,100.71 hectares of the total area of Yogyakarta, 3,250 hectares (Government of Yogyakarta City,2014). The increasing population and the greater the amount of land that is used for the settlements/residential area will lead to the increasing amount of fuel consumption for cooking needs. Considering PP No. 61 Year 2011 regarding the National Action Plans for Reducing the Greenhouse Gasses Emission and PP No. 71 Year 2011 about conducting an inventory for greenhouse gasses which states that each regional govermental area of district or city is obliged to conduct an inventory of greenhouse gasses, this research became of an importance.. This research aims at estimating the carbon footprint and performing the mapping of carbon emission in Yogyakarta. The result shows that the calculations of carbon emissions in each sub-district showed the highest emission is on Gedontengen sub-district in the amount of 994,033 tons $\mathrm{CO}_{2} /$ household.year and the lowest emission is on Pakualaman sub-district in the amount of 20,811 tons $\mathrm{CO}_{2} /$ household.year. Based on the mapping result, it can be known that 3 subdistricts out of the 14 sub-district are at very high scale emission, 994,000 - 528,000 tons $\mathrm{CO}_{2} /$ household.year, 3 subdistricts are at high scale emission of 528,000 - 186,000 tons $\mathrm{CO}_{2} /$ year.household, 1 sub-district is at middle scale of 95,000 tons $\mathrm{CO}_{2} /$ household.year. Five sub-districts are at low scale emission of 95,000-34,460 tons $\mathrm{CO}_{2} /$ household.year and 2 sub-districts are on very low scale emission of $34,460-20,811$ tons $\mathrm{CO}_{2} /$ household.year.
\end{abstract}

Keywords : $\mathrm{CO}_{2}$ Emission, IPCC, Yogyakarta City, Household Cooking Fuel, Mapping

Dikirim/submitted: 10 November 2016

Diterima/accepted: 10 Desember 2016 


\section{PENDAHULUAN}

Udara merupakan komponen kehidupan yang sangat penting bagi manusia. Namun, seiring dengan perkembangan zaman diikuti dengan berbagai macam aktivitas yang dilakukan manusia menyebabkan menurunnya kualitas udara. Hampir segala sektor dalam kehidupan seperti transportasi, industri dan juga kegiatan permukiman dapat berkontribusi pada penurunan kualitas udara. Beberapa kegiatan permukiman menghasilkan emisi yang dapat menurunkan kualitas udara. Salah satunya adalah kegiatan memasak dimana dalam kegiatan memasak menggunakan bahan bakar yang dapat menghasilkan emisi udara di antaranya senyawa organik volatil/Volatile Organic Compounds (VOC). Emisi pembakaran bahan bakar memasak ini merupakan sumber utama penghasil VOC di atmosfer perkotaan (Cheng, dkk., 2016). Selain VOC, emisi yang dihasilkan dari kegiatan memasak adalah Gas rumah kaca (Permadi, dkk., 2017) serta masih banyak lagi. Gas rumah kaca sendiri memberi dampak buruk salah satunya perubahan iklim, dimana menyebabkan presipitasi meningkat sampai 50\% bahkan lebih sehingga meningkatkan potensi terjadinya banjir (Elizbarashvili, dkk., 2017).

Semakin meningkat jumlah penduduk maka semakin meningkatkan emisi gas rumah kaca khususnya karbon dioksida. Menurut Dhakal (2010), sumber utama emisi gas rumah kaca yang banyak dikaji adalah karbondioksida $\left(\mathrm{CO}_{2}\right)$. Hal tersebut cukup beralasan, mengingat karbondioksida $\left(\mathrm{CO}_{2}\right)$ merupakan salah satu gas yang banyak dihasilkan di wilayah perkotaan atau urban, terutama dari sektor rumah tangga. Data yang dihimpun dari Kementrian Negara Lingkungan Hidup Indonesia menunjukan bahwa sektor energi memberikan sumbangan terbesar gas rumah kaca, khususnya $\mathrm{CO}_{2}$ yang bersumber dari permukiman salah satunya dari penggunaan bahan bakar memasak.

Peningkatan emisi yang dihasilkan dari kegiatan memasak akan seiring dengan peningkatan jumlah penduduk dan luas penggunaan lahan yang didominasi oleh perumahan. Di Kota Yogyakarta, penggunaan lahan untuk kawasan perumahan mencapai 2.100,71 Ha dari total luas lahan Kota Yogyakarta, yakni 3.250 Ha (Pemerintah Kota Yogyakarta, 2014). Menurut Widodo, dkk. (2015), pertumbuhan daerah permukiman menyebabkan beberapa masalah di antaranya harga penjualan lahan yang menjadi lebih mahal, banyaknya makelar tanah, masalah kepemilikan lahan dan lain-lain. Semakin meningkat jumlah penduduk, maka semakin besar lahan yang dipergunakan untuk perumahan/permukiman, hal ini akan menyebabkan semakin besar kebutuhan penggunaan bahan bakar untuk kegiatan memasak. 
Penelitian ini menjadi penting untuk dibahas karena hal tersebut dikaitkan dengan adanya PP No. 61 Tahun 2011 tentang rencana Aksi Nasional Penurunan Emisi GRK dan PP No. 71 Tahun 2011 tentang Penyelenggaraan Inventarisasi Emisi GRK Nasional yang menyatakan bahwa setiap daerah pemerintahan daerah kabupaten/kota wajib melakukan kegiatan inventarisasi GRK. Sehingga hasil penelitian ini nantinya dapat membantu menghitung inventarisasi emisi GRK (karbondioksida) untuk Kota Yogyakarta menggunakan metode IPCC (Intergovernmental Panel on Climate Change).

Setelah perhitungan estimasi tapak karbon/emisi GRK karbondioksida diperoleh, maka akan dilakukan pemetaan terhadap wilayah studi sehingga dapat dilihat tapak karbon yang ada di kota Yogyakarta. Selanjutnya hasil pemetaan yang telah diperoleh akan dapat digunakan untuk pengembangan wilayah tersebut agar dapat merata, dalam artian apabila hasil estimasi tapak karbon yang didapatkan tinggi maka tidak akan dilakukan pengembangan yang dapat meningkatkan emisi agar pencemaran di daerah tersebut tidak semakin meningkat.

\section{METODE PENELITIAN}

Pada penelitian ini dilakukan analisis beban emisi karbon melalui pendekatan nilai faktor misi yang terdapat dalam Intergovernmental Panel on Climate Change (IPCC) Guidelines (2006). Dimana data primer yang digunakan pada penelitian ini adalah penggunaan bahan bakar (LPG, minyak tanah, arang dan kayu bakar) meliputi volume penggunaannya. Data primer tersebut diperoleh dari survei lapangan dan kuisioner yang dilakukan pada bulan September 2016. Data sekunder yang dibutuhkan pada penelitian ini yaitu jumlah kepala keluarga (KK) dan peta Kota Yogyakarta. Penentuan jumlah sampel rumah tangga yang akan digunakan sebagai sampel, menggunakan rumus Krejcie dan Morgan (1970). Metode sampling yang digunakan adalah metode sampling stratifikasi dimana rumus yang digunakan untuk penenutuan jumlah sampel menggunakan Krejcie dan Morgan dikarenakan rumus tersebut dapat berlaku umum termasuk dalam penentuan jumlah sampel. Rumus Krecjie dan Morgan (1970) berserta contoh perhitungannya dapat dilihat pada persamaan 1 berikut.

$$
n=\frac{x^{2} N P(1-P)}{(N-1) d^{2}+x^{2} P(1-P)}
$$


Dimana :

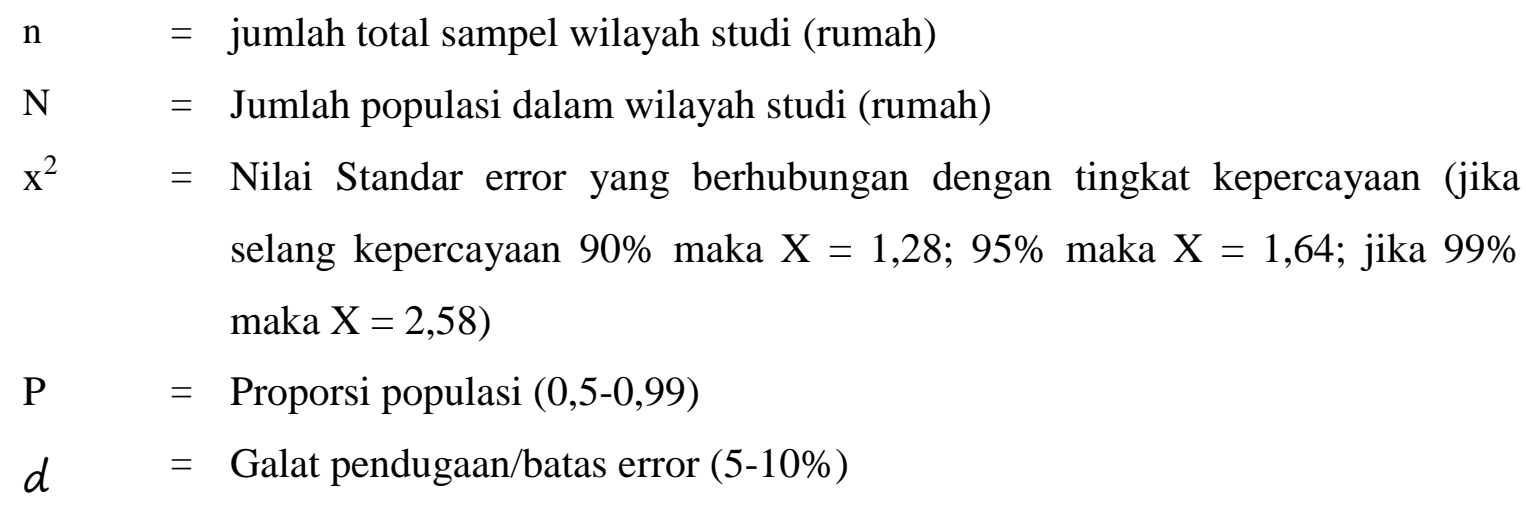

Setelah dilakukan perhitungan jumlah sampel yang diambil, kemudian dilakukan perhitungan jumlah sampel rumah tangga yang akan diambil di tiap kecamatan dengan menggunakan persamaan 2 berikut :

$$
\mathrm{n}_{\mathrm{i}}=\mathrm{n}\left(\frac{N \mathrm{i}}{N}\right)
$$

Dimana :

$$
\begin{array}{ll}
\mathrm{Ni} & =\text { Jumlah populasi pada masing-masing wilayah studi } \\
\mathrm{N} & =\text { Jumlah total populasi wilayah studi } \\
\mathrm{n} & =\text { Jumlah total sampel wilayah studi } \\
\mathrm{n}_{\mathrm{i}} & =\text { Jumlah sampel pada masing-masing wilayah studi }
\end{array}
$$

Untuk perhitungan jumlah sampel yang akan diambil di lapangan akan dijelaskan pada persamaan 3 berikut :

$$
n=\frac{(1,64)^{2}(130380)(0,5)(1-0,5)}{(130380-1)(0,1)^{2}+(1,64)^{2}(0,5)(1-0,5)}=67 \text { Sampel }
$$

Setelah mendapatkan jumlah keseluruhan sampel kemudian dilakukan perhitungan jumlah sampel yang akan diambil per kecamatan yang akan dijelaskan pada persamaan berikut (contoh jumlah sampel yang akan diambil adalah klasifikasi I):

$$
\mathrm{n}_{\mathrm{i}}=67\left(\frac{33482}{130380}\right)=18 \text { sampel }
$$

untuk perhitungan jumlah sampel per kecamatan dapat dilihat pada Tabel 1 berikut : 
Tabel 1. Jumlah Sampel Rumah Tangga yang Diambil

\begin{tabular}{lcc}
\hline Klasifikasi & $\begin{array}{c}\text { Jumlah Rumah } \\
\text { Tangga }\end{array}$ & $\begin{array}{c}\text { Jumlah Sampel Per } \\
\text { Klasifikasi }\end{array}$ \\
\hline $\begin{array}{c}\text { Klasifikasi I } \\
\text { (Daerah Cepat Maju dan } \\
\text { Tumbuh) }\end{array}$ & & 18 \\
\hline $\begin{array}{c}\text { Klasifikasi II } \\
\text { (Daerah Maju Tapi Tertekan) }\end{array}$ & 33482 & 11 \\
\hline $\begin{array}{c}\text { Klasifikasi III } \\
\text { (Daerah Berkembang Cepat) }\end{array}$ & 21007 & 13 \\
\hline $\begin{array}{c}\text { Klasifikasi IV } \\
\text { (Daerah Relatif Tertinggal) }\end{array}$ & 25360 & 25 \\
\hline Tumber : Data Primer, 2016 & & \\
\hline
\end{tabular}

Pengambilan sampel acak statifikasi dimana sampel diambil berdasarkan analisis Tipologi Klassen dimana analisis tersebut membagi wilayah berdasarkan 2 indikator utama yaitu, pertumbuhan ekonomi dan pendapatan perkapita.

Adapun rumus yang digunakan untuk menghitung emisi karbon berdasarkan IPCC (2006) adalah sebagai berikut :

$$
\text { Emisi } \mathrm{CO}_{2}=\text { Konsumsi Bahan Bakar x FE x NCV }
$$

Keterangan :

Emisi $\mathrm{CO}_{2}$

$=$ Jumlah Emisi CO 2 (Satuan Massa)

Konsumsi Bahan Bakar

$=$ Konsumsi Bahan Bakar (Kg/Tahun)

FE

$$
=\text { Faktor Emisi Bahan Bakar (ton } \mathrm{CO}_{2} \text { ) }
$$

$\mathrm{NCV}$ $=$ Nilai Net Calorific Value (energy content) per unit massa atau

Volume bahan bakar (TJ/ton fuel)

Nilai faktor emisi dan nilai kalor tergantung pada bahan bakar yang digunakan. Perhitungan emisi yang dihasilkan dari bahan bakar tersebut menggunakan pendekatan nilai faktor-faktor emisi dan Net Calorific Value bahan bakar LPG, minyak tanah, arang dan kayu bakar yang dapat dilihat pada Tabel 2 berikut : 
Tabel 2. Nilai Faktor Emisi dan NCV Masing-Masing Bahan Bakar

\begin{tabular}{ccc}
\hline Bahan Bakar & $\begin{array}{c}\text { Faktor Emisi } \\
\text { (Kg CO2 /T) }\end{array}$ & NCV (TJ/Kg) \\
\hline LPG & 63100 & $47,3 \times 10^{-6}$ \\
Kayu Bakar & 112000 & $15 \times 10^{-6}$ \\
Arang & 112000 & $29,5 \times 10^{-6}$ \\
Minyak Tanah & 71900 & $43,8 \times 10^{-6}$ \\
\hline
\end{tabular}

Sumber : IPCC, 2006

Kemudian hasil analisis dan hasil survey lapangan, selanjutnya dilakukan perhitungan emisi $\mathrm{CO}_{2}$ setiap kecamatan. Dari hasil perhitungan emisi tiap kecamatan tersebut maka dilakukan pemetaan sebaran emisi $\mathrm{CO}_{2}$ per kecamatan di wilayah Kota Yogyakarta.

\section{HASIL DAN PEMBAHASAN}

Berdasarkan kuisioner yang disebarkan, diperoleh hasil bahwa masyarakat Kota Yogyakarta menggunakan LPG, minyak tanah dan biomassa (arang dan kayu bakar) sebagai bahan bakar memasak. Adapun persentase penggunaan bahan bakar tersebut dapat dilihat pada Gambar 1.

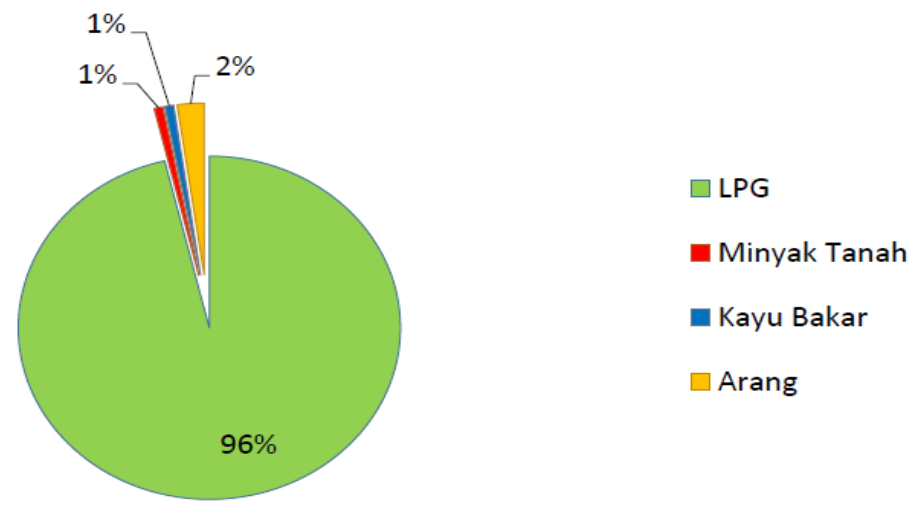

Gambar 1. Prosentase Penggunaan Bahan Bakar Memasak di Kota Yogyakarta

Setelah jumlah penggunaan bahan bakar memasak diperoleh maka selanjutnya dilakukan perhitungan estimasi besaran emisi karbon $\mathrm{CO}_{2}$ yang dihasilkan dan diperoleh hasilnya sebesar 2.911,71 ton $\mathrm{CO}_{2}$ /tahun, untuk persebaran emisi $\mathrm{CO}_{2}$ dan konsumsi bahan bakar memasak tiap kecamatan dapat dilihat pada Gambar 2 berikut : 


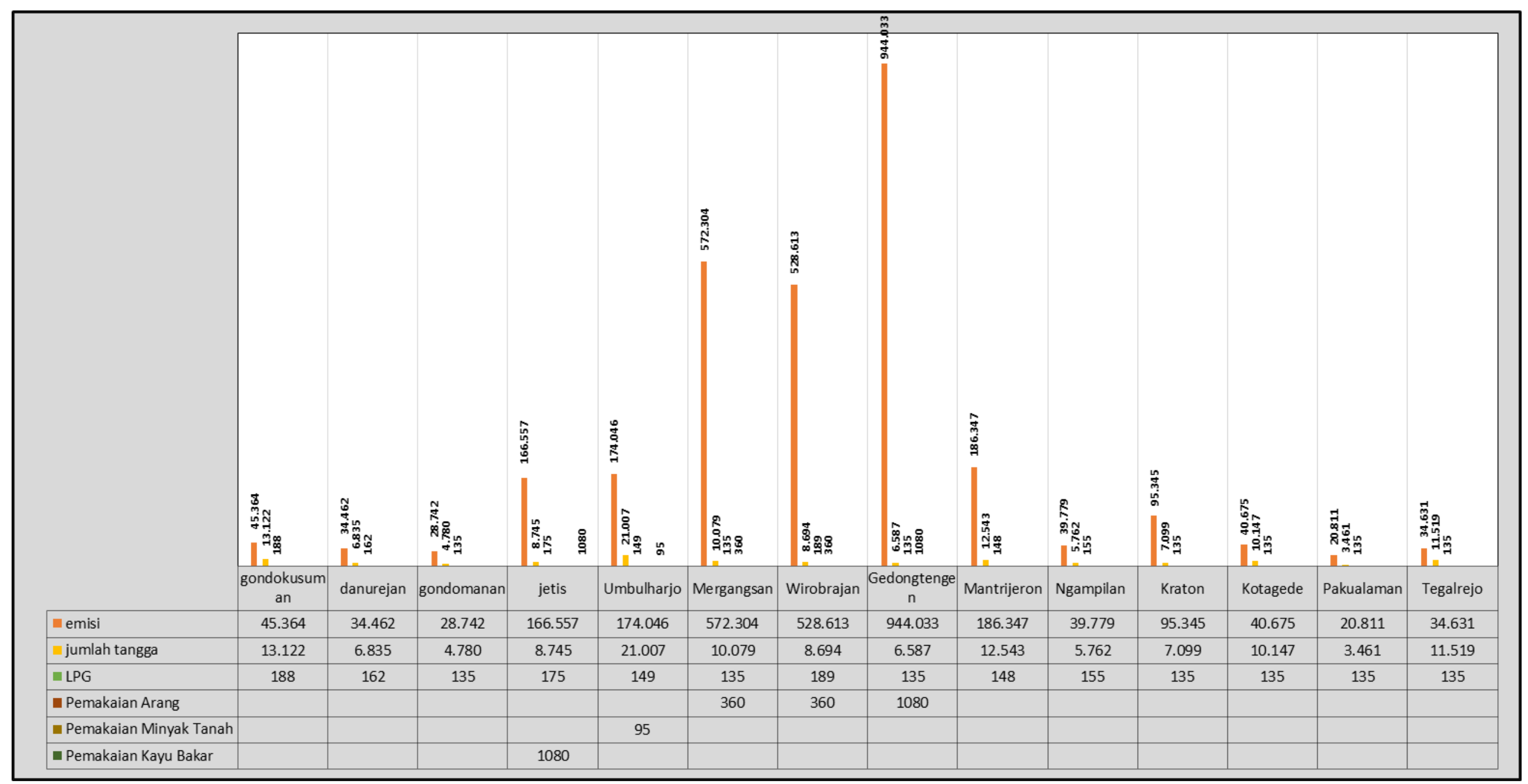

Gambar 2. Emisi $\mathrm{CO}_{2}$ yang Dihasilkan dari Penggunaan Bahan Bakar untuk Memasak tiap Kecamatan dalam Satuan Kg 
Dari Gambar 2. tersebut maka dapat dilihat bahwa emisi karbon $\mathrm{CO}_{2}$ yang paling tinggi adalah pada Kecamatan Gedongtengen yaitu sebesar 994,03 ton $\mathrm{CO}_{2} /$ tahun dibandingkan dengan kecamatan yang lainnya. Hal tersebut dikarenakan pemakaian bahan bakar memasak di kecamatan tersebut lebih dari satu jenis yaitu LPG dan arang. Dimana penggunaan bahan bakar arang cukup besar. Faktor emisi dan nilai kalor arang diketahui paling besar untuk $\mathrm{CO}_{2}, \mathrm{CO}$ and $\mathrm{PM}_{2,5}$ sehingga berpotensi menghasilkan emisi $\mathrm{CO}_{2}$ yang besar. Untuk menurunkan emisi dari penggunaan arang sebaiknya diganti menjadi briket arang sebelum digunakan karena briket arang terbukti dapat menurunkan emisi $\mathrm{CO}_{2}, \mathrm{CO}$ and $\mathrm{PM}_{2,5}$ masing-masing 60\%, 72\%, 88\% dibandingkan penggunaan arang itu sendiri (Njenga, dkk., 2014).

Emisi karbondioksida yang paling rendah adalah pada Kecamatan Pakualaman yaitu sebesar 20,81 ton $\mathrm{CO}_{2} /$ tahun. Hal ini dikarenakan jumlah rumah tangga di Kecamatan Pakualaman yang paling sedikit dan penggunaan pola konsumsi bahan bakar memasak yang termasuk paling rendah. Begitu pula dengan jenis bahan bakar memasak yang digunakan di Kecamatan Pakualaman yaitu hanya menggunakan bahan bakar jenis LPG. Selain itu Kecamatan Pakualaman termasuk dalam klasifikasi wilayah dengan pertumbuhan ekonomi dan pendapatan yang rendah, hal yang bisa menyebabkan emisi karbondioksida di Kecamatan Pakualaman masih rendah dan juga bisa jadi dikarenakan pola perilaku rumah tangga yang diberada di Kecamatan Pakualaman adalah rumah tangga yang tidak boros dalam pemakaian bahan bakar. Menurut Boedisantoso (2016), bagi penghuni rumah yang sibuk dan sering berada di luar rumah, maka pengunaan bahan bakar memasaknya pun akan lebih sedikit dibandingkan penghuni yang sering berada di dalam rumah. Sehingga emisi yang dihasilkan pun masih rendah dan sedikit. Menurut Rahut, dkk. (2015), terdapat beberapa faktor yang mempengaruhi suatu rumah tangga atau permukiman memilih bahan bakar untuk memasak diantaranya tingkat pendidikan kepala rumah tangga, perekonomian, jenis kelamin dan lokasi permukiman. Sejalan dengan itu Karimu, dkk. (2016) dalam penelitian yang dilakukan di Ghana juga menyimpulkan bahwa selain pendidikan, perekonomian serta lokasi permukiman, akses menuju infrastruktur permukiman, ketersediaan pasokan LPG, merupakan beberapa faktor dalam memilih LPG sebagai bahan bakar memasak di Ghana.

Alternatif yang dapat dilakukan untuk mengurangi emisi $\mathrm{CO}_{2}$ yang dihasilkan dari penggunaan bahan bakar LPG menurut Gomez, dkk. (2016) adalah penggunaan kompor listrik dan atau kompor induksi. Emisi $\mathrm{CO}_{2}$ yang dihasilkan selama memasak menggunakan LPG paling besar, disusul dengan kompor listrik dan yang terkecil adalah kompor induksi. 
Setelah mengetahui total emisi $\mathrm{CO}_{2}$ dari penggunaan bahan bakar memasak di Kota Yogyakarta, selanjutnya tingkat emisi dari tiap kecamatan digambarkan dalam bentuk peta. Peta tersebut menunjukan tingkat emisi $\mathrm{CO}_{2}$ berdasarkan skala dari tiap wilayah kecamatan yang digolongkan menjadi 5 (lima) tingkatan sesuai dengan tingkat emisi di masing-masing wilayah. Hasil pemetaan dapat dilihat pada Gambar 3 berikut.

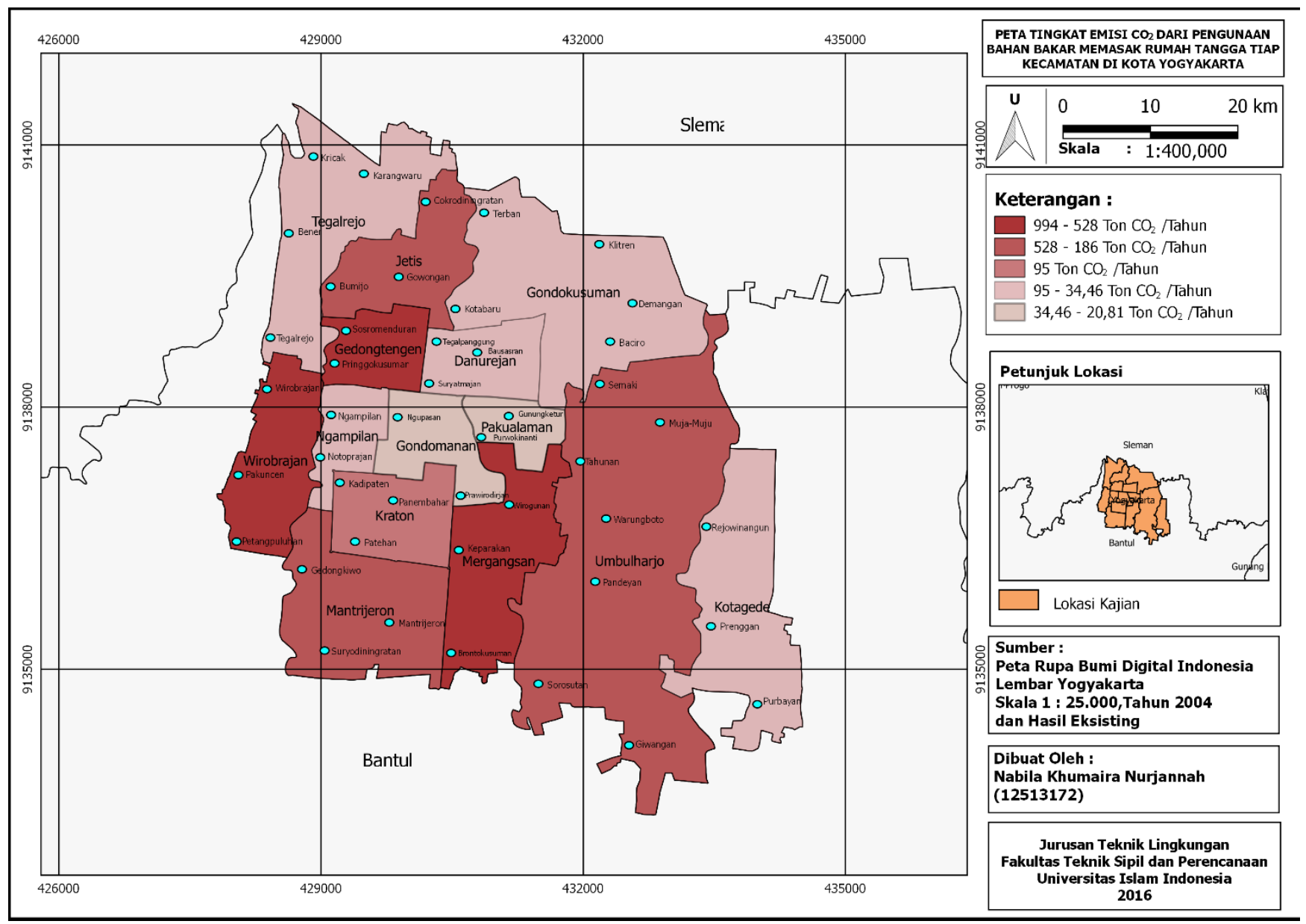

Gambar 3. Pemetaan Tingkat Emisi $\mathrm{CO}_{2}$ Dari Penggunaan Bahan Bakar Memasak Rumah Tangga di Tiap Kecamatan Kota Yogyakarta

Berdasarkan hasil pemetaan dapat diketahui bahwa dari 14 kecamatan ada 3 kecamatan berada pada emisi skala sangat tinggi 994 - 528 ton $\mathrm{CO}_{2} /$ rumah tangga.tahun, 3 kecamatan berada pada emisi skala tinggi 528 - 166,5 ton $\mathrm{CO}_{2} /$ rumah tangga.tahun, 1 kecamatan berada pada skala emisi sedang 95.000 ton $\mathrm{CO}_{2} /$ rumah tangga.tahun, 5 kecamatan berada pada skala rendah $95-34,46$ ton $\mathrm{CO}_{2} /$ rumah 
tangga.tahun, dan 2 kecamatan berada pada skala sangat rendah 34,46 - 20,811 ton $\mathrm{CO}_{2} /$ rumah tangga.tahun.

Menurut Rachmawati (2015), tingkat perubahan lahan yang disertai dengan tingkat laju pertumbuhan penduduk yang menyebabkan peningkatan jumlah penduduk dan berakibat pada meningkatnya lahan untuk permukiman, hal ini juga dapat dilihat dari penelitian yang dilakukan di Kota Yogyakarta yang kepadatan penduduknya pada tahun 2015 sebesar 12.669 jiwa $/ \mathrm{km}^{2}$ serta laju pertumbuhan penduduk yang mencapai 1,02 persen per tahun dan penggunaan lahan di Kota Yogyakarta sangat besar, hal ini sesuai dengan RTRW Kota Yogyakarta yang dominasi guna lahan adalah perumahan/permukiman. Dengan meningkatnya jumlah permukiman di Kota Yogyakarta akan berakibat pada peningkatan emisi yang dihasilkan dari aktivitas rumah tangga khususnya peningkatan emisi $\mathrm{CO}_{2}$ dari aktivitas memasak.

\section{KESIMPULAN}

Dari hasil penelitian yang dilakukan dapat ditarik kesimpulan bahwa penggunaan bahan bakar memasak LPG menghasilkan emisi karbon $\mathrm{CO}_{2}$ lebih kecil dibandingkan dengan penggunaan bahan bakar memasak minyak tanah dan biomassa seperti arang dan kayu bakar. Hal ini dikarenakan nilai faktor emisi dari LPG lebih kecil dan nilai kalor yang lebih besar dibandingkan minyak tanah dan biomassa. Semakin tinggi nilai kalor maka faktor emisi yang dimiliki semakin kecil karena pembakaran yang terjadi lebih sempurna. Perubahan yang dapat dilakukan dalam rangka menurunkan emisi karbon $\mathrm{CO}_{2}$ salah satunya adalah penggantian bahan bakar memasak dari minyak tanah dan biomassa (arang dan kayu bakar) menjadi LPG. Emisi akan lebih kecil lagi bila penggunaan LPG diganti menjadi listrik bahkan kompor induksi. Hal ini mengingat beberapa rumah di Kota Yogyakarta masih ada yang menggunakan bahan bakar biomassa untuk memasak. Faktor lain yang mempengaruhi dari besar kecilnya emisi $\mathrm{CO}_{2}$ yang dihasilkan dari penggunaan bahan bakar memasak adalah pola konsumsi bahan bakar memasak, jumlah rumah tangga, serta pertumbuhan ekonomi dan pendapatan perkapita suatu daerah.

\section{UCAPAN TERIMA KASIH}

Penulis mengucapkan terimakasih kepada DPPM (Direktorat Penelitian dan Pengabdian Masyarakat) Universitas Islam Indonesia yang telah mendukung berlangsungnya penelitian ini dari awal hingga selesai. 


\section{DAFTAR PUSTAKA}

Boedisantoso, Rachmat. 2016. Pengembangan Metode Perhitungan Emisi $\mathrm{CO}_{2}$-e dari Limbah Tinja dan Penggunaan bahan bakar LPG Aktivitas Rumah Tangga (Studi Kasus: Kota Surabaya). Surabaya: Institut Teknologi Sepuluh November.

Cheng, S., Wang, G., Lang, J., Wen, W., Wang, X., Yao, S. 2016. Characterization of Volatile Organic Compounds from Different Cooking Emission. Atmospheric Environment 145 (2017) 299-307.

Dhakal, S. 2010. GHG Emissions From Urbanization and Opportunities for Urban Carbon Mitigation. Current Opinion in Environmental Sustainbility Vol. 2, 277-283.

Elizbarashvili, M., Elizbarashvili, E., Tatishvili, M., Elizbarashvili, S., Meskhia, R., Kutaladze, N., King, L., Keggenhoff, I., Khardziani, T. 2017. Georgian Climate Change Under Global Warming Condistions. Annals of Agrarian Science 1-9

Gomez, J. M., Ibarra, D., Villacis, S., Cuji, P., Cruz, P. R. 2016. Analysis of LPG, Electric and Induction Cookers During Cooking Typical Ecuadorian Dishes into the National Efficient Cooking Program. Food Policy 59 88-102.

Intergovernmental Panel on Climate Change (IPCC). (2006). “Guidelines for National Greenhouse Gas Inventories". Institute for global environmental strategies (IGS), Hayama, Japan.

Karimu, Amin., Mensah, J. T., Adu, George. 2016. Who Adopts LPG as The Main Cooking Fuel and Why? Emipirical Evidence on Ghana Based on National Survey. World Development Vol 85, pp. 43-57

Krejcie, Robert V., Morgan, Daryle W. (1970). Determining Sample Size for Research Activities. Educational and Psychological Measurement.

Njenga, M., Karanja, N., Karlsson, H., Jamnadass, R., Iiyama, M., Kithinji, J., Sundberg, C. (2014). Additional Cooking Fuel Suplly and Reduced Global Warming Potential from Recycling Charcoal Dust into Charcoal Briquette in Kenya. Journal of Cleaner Production 81 81-88.

Peraturan Presiden No. 61. (2011). Tentang Rencana Aksi Nasional Penurunan Emisi Gas Rumah Kaca.

Peraturan Presiden No. 71. (2011). Penyelenggaran Inventarisasi Gas Rumah Kaca Nasional. 
Pemerintah Kota Yogyakarta Provinsi Daerah Istimewa Yogyakarta. (2014). Laporan Status Lingkungan Hidup Daerah Kota Yogyakarta.

Permadi, A., D, Sofyan Asep, Oanh, N., T., K. (2017). Assesment of Emissions of Greenhouse Gases and Air pollutants in Indonesia and Impact of National Policy for Elimination of Karosene Use in Cooking. Atmospheric Environment 154 (2017) 82-94.

Rachmawati, Veny. (2015). Penentuan Faktor Emisi Spesifik Untuk Estimasi Tapak Karbon Dan Pemetaannya Dari Penggunaan Bahan Bakar Di Kabupaten Sidoarjo. Prosiding Seminar Nasional Manajemen Teknologi XXII. Surabaya : Institut Teknologi Sepuluh November.

Rahut, D. B., Behera, Bhagirath., Ali, Akhter. (2016). Patterns and Determinants of Household Use of Fuels for Cooking: Empirical Evidence from Sub-Saharab Africa. Energy 117 93-104

Widodo, B., R. Lupyanto, B. Sulistiono, D. A. Harjito, J. Hamidin, E. Hapsari, Yasin, M., Ellinda, C. (2015). Analysis of Environmental Carrying Capacity for the Development of Sustainable Settlement in Yogyakarta Urban Area. Procedia Environmental Sciences 28 519-527. 